\title{
Dynamics performance of the wind-power supply chain with transmission capacity constraints
}

\author{
Milton M. Herrera ${ }^{1}$, Mauricio Uriona ${ }^{2}$, Isaac Dyner ${ }^{3}$ \\ ${ }^{1}$ Economic Sciences Research Centre, Universidad Militar Nueva Granada, Colombia \\ ${ }^{2}$ Department of Industrial and Systems Engineering, Federal University of Santa Catarina, Brazil \\ ${ }^{1,3}$ Engineering Department, Universidad Jorge Tadeo Lozano, Colombia
}

\begin{tabular}{l} 
Article Info \\
\hline Article history: \\
Received Mar 27, 2019 \\
Revised Oct 7, 2019 \\
Accepted Oct 17, 2019 \\
\hline
\end{tabular}

\section{Keywords:}

Capacity

Simulation

Supply chain

Transmission

Wind power

\begin{abstract}
Previous studies have shown that poor performance of energy supply chains arises from incorrectly interpret feedback information and time delays between decisions and actions in energy policy. This paper assesses alternatives to improve performance of wind-power supply chain with transmission constraints that contribute to enhance response capacity of the wind industry to changes of energy policy. In order to test these alternatives, this paper used a simulation model with system dynamics (SD), taking as case study Brazil. The simulation model represents the main time lags and fluctuations that exist in the wind-power supply chain. Four simulation scenarios were proposed to evaluate changes in auction-based policy in wind industry of Brazil. The results are related to operational capacity, inventory levels and response capacity. This paper provides an analysis of different scenarios that contribute with synchronization of auctions policy, including transmission capacity constraints.
\end{abstract}

Copyright (c) 2020 Institute of Advanced Engineering and Science. All rights reserved.

\section{Corresponding Author:}

Milton M. Herrera,

Economic Sciences Research Centre,

Universidad Militar Nueva Granada,

Carrera 11 \# 101-80, Bogotá, Colombia.

Email: milton.herrera@unimilitar.edu.co

\section{INTRODUCTION}

Since renewable energy is a tech-intensive industry, which requires a large amount of investment and a high level of technology innovations, developers of supply chain face many risks when doing an energy project [1]. For instance, in some countries, a production increase of components still tends to be limited by logistical bottlenecks as well as high freight cost for large blades, turbines and towers to be located in remote areas [2, 3]. Another obstacle is the insufficient high voltage network that interconnects the transmission system and wind farms to complement the National Interconnected System (NIS) affect the energy supply [4-6]. This obstacle generated due to the accumulated time-delays in the construction of transmission infrastructure [7]. Also, most energy policy for renewable does not take into account that emissions depend on the location of power plants [5]. Thus, the bottlenecks caused by operational delays [8], construction delays of transmission capacity [9] and location of facilities [5] could affect to supply chain performance [10]. In this context, this paper assesses changes on energy policy for understanding behaviour of supply chain capacity to provide components and parts of the wind industry on time, including transmission capacity constraints in the energy system.

In the last years, renewable energy has become for several countries an alternative to reduce dependence on fossil fuels [11-15]. Currently, the Brazilian power system supported on an auctions-based mechanism to promote supply expansion for the regulated market. Given the role of wind industry for the Brazilian electricity market, this paper surveys unsynchronised energy policy related with time-delays of 
construction of transmission lines and recent changes of the auctions' policy in practice that affects the development of wind-power supply chain. Despite an increase of auctions for transmission lines in the last year, Brazilian electricity market faces drawback related with the delays to build extensive transmission network for energy supply [7], [16-18]. Currently, reduction in auctions in the short term, as present in Figure 1, and the more considerable variability of electricity prices in the medium and long term represents a significant challenge for wind industry investments. Considering the current unfavourable scenario, the construction of wind farms and an insufficient of transmission lines, a question arises: How the wind-power supply chain development could be affected by time-delays in transmission infrastructure and cancellation of the auctions?

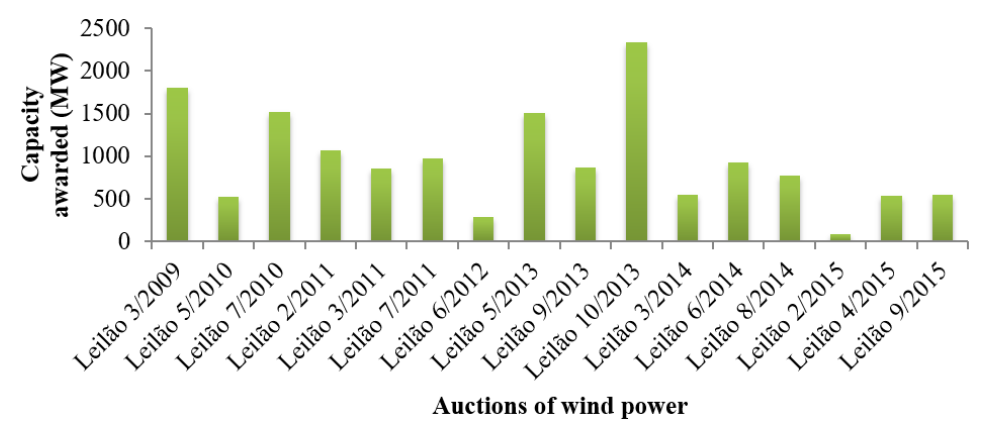

Figure 1. Capacity awarded through auctions of wind power in Brazil Source: Own elaboration based on [19]

Several studies support the relation between industrial impacts and energy policy [9, 15, 20, 21]. That is, supply chain decision-making is inevitably influenced by the orientation of the government's energy policy [1]. In the case of Brazil, the Federal Government increased its attractiveness for local manufacturing by establishing an incentive's policy to support wind industry development. However, this support mechanism for renewable power does not take into account delays caused by environmental licences or construction time of infrastructure, which impacting wind industry in the long term [22-24]. Consequently, this situation generates an asynchrony along the supply chain.

The modelling and simulation method of SD was first proposed by Forrester [25] to analyse complex behaviours through computer simulations [26, 27]. For several years, the SD has been a useful mathematical modelling technique for understanding and discussing complex issues in the electricity industry [26, 28-32]. Although different optimization methods and econometrics have been used in order to facilitate decision-making on the electricity industry, these methods are not used to obtain the future dynamic behaviour due to its limiting to understand the delays of energy system [31]. In contrast, SD offers an attractive way of understanding how asynchrony and synchrony of political decisions may affect wind-power supply chain development over time. This paper presents a simulation model using SD to assess four scenarios aimed to analyse implications of auctions-policy on wind power supply chain, such as average inventory level, capacity of production for each actor and the capacity level of response.

\section{RESEARCH METHOD}

The simulation model allows better understand the asynchrony caused by the auctions' cancellation of wind power and delays on transmission infrastructure. The modelling approach considers the following steps: the development of a dynamic hypothesis, simulation model and policy analysis through simulation scenarios.

\subsection{Causal structure of the model}

This research contributes to the analysis of wind power supply chain proposing a causal structure for understanding the dynamics of the electricity sector in Brazil. The dynamics and structural complexities of the wind power supply chain taken into account in the detailed SD model. Figure 2 shows the causal loop diagram (CLD) that represents the flows between the main variables of the simulation model. Loops B1 and B2 represent the demand-supply balancing and building capacity of wind industry (market diffusion), respectively. Both B3 and B4 represent the drawbacks associated with the asynchrony of energy policies. When a country incentivizes new generation capacity without coordination with network expansion, it may

Dynamics performance of the wind-power supply chain with transmission capacity ... (Milton M. Herrera) 
risk the security of supply. Loop B4 demonstrates that generation expansion could be limited when occurring transmission congestion due to insufficient transmission capacity. Also, loop B3 shows how a change in auctions policy affects the installed capacity of wind power, which depends on contracted auctions by the federal government.

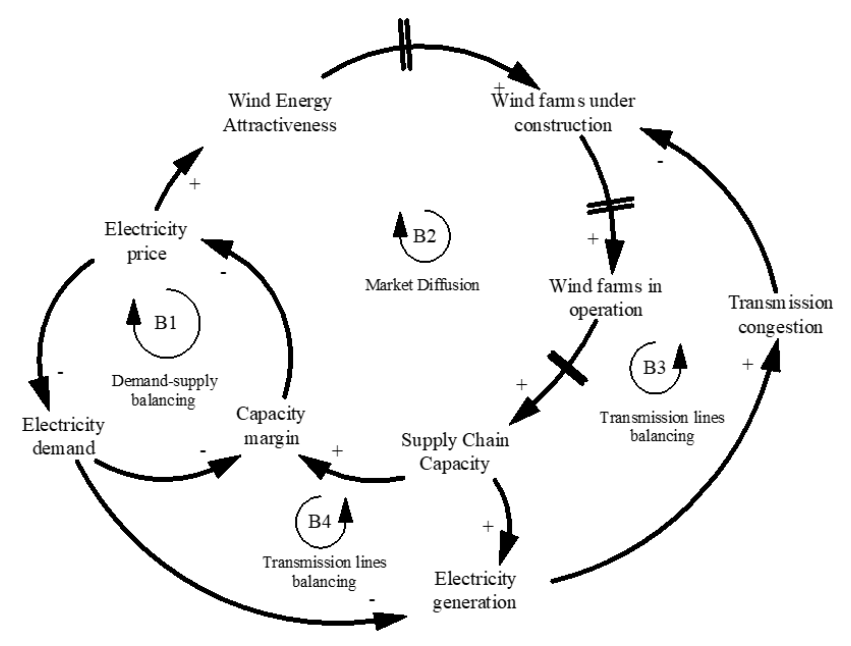

Figure 2. CLD representing the dynamics of auctions-based policy in Brazil for transmission and generation

\subsection{Model assumptions and data}

Data availability and quality are permanently concerns for all modelling studies [33]. Thus, this study makes the following underlying assumptions to quantify the structure model and build a complete system dynamics model.

a. The simulation model used the database of the Brazilian energy agency ANEEL, which publishes the auctions rounds for the contracted capacity of wind power that took place in the period between December 2009 and December 2017.

b. To validate and evaluate the dynamic behaviour, the model employed the time series of the installed capacity projection of wind power obtained by [34].

c. The simulation model takes into account the values of average bids considering the variation of electricity demand.

d. Other generation technologies considered within the model. The initial data on the installed capacity of each technology corresponds to the year 2018, according to Brazil's energy matrix reported by [35]. This assumption is taken into account to calculate the market share expansion of the Brazilian wind power.

e. Over $31 \%$ of the wind projects that established a power purchase agreement in 2010 had been affected by network delays by the time the implementation deadline was research in 2013 [23]. Thus, one assumption made in the simulation model is that transmission congestion reached was $30 \%$ per year, including grid load loss.

\subsection{Simulation scenarios}

The analysis of the changes in the political decision faced the Brazilian market due to cancellation of wind auctions and transmission infrastructure delays provide essential elements to the evaluation of alternatives energy-policies for wind power supply chain. Table 1 shows the proposed design of four scenarios to evaluate the auction-based policy reform until the year 2030. The first scenario represents the current conflict of energy policy related to the cancellation of auctions and delays transmission lines (business as usual, BAU). The second scenario benefice the expansion of transmission infrastructure with suitable capacity and limiting the growth of wind power generation with the cancellation of auctions. While for the third scenario, the auctions round for contracted capacity of wind power is continuous but uncoordinated with transmission infrastructure projects. The final scenario is coordinated auctions policy and appropriates between both expansions of wind power and transmission infrastructure. Scenario 4 is given as the process by which stakeholders adopt a high level of cooperation and planning (see, [36]). Mutual and integral planning to the future and a balanced power relationship are essential to this scenario. Simulation 
scenarios 2 and 4 are characterised by low levels of congestion, while scenarios 1 and 3 are quite the opposite. The four scenarios are evaluated to measure the supply chain performance caused by the reform of auction policy.

Table 1. Scenarios for analysing unsynchronised policies impact on wind power supply chain

\begin{tabular}{lll}
\hline & \multicolumn{1}{c}{ Definition of scenarios } & \multicolumn{1}{c}{ Characteristics } \\
\hline Scenario 1 & Business as usual (BAU) & $\begin{array}{l}\text { This scenario assumes that the current conditions are preserved in } \\
\text { the future. In this scenario is presented the cancellation of wind } \\
\text { auctions and insufficient transmission lines. }\end{array}$ \\
Scenario 2 & $\begin{array}{l}\text { Insufficient auctions for wind generation, } \\
\text { but sufficient for transmission lines }\end{array}$ & $\begin{array}{l}\text { This scenario assumes an increase of } 1.8 \text { GW in the wind power } \\
\text { contracting every two years. While for transmission lines assumes } \\
\text { a suitable capacity without congestion. }\end{array}$ \\
Scenario 3 & $\begin{array}{l}\text { Sufficient auctions for wind generation, } \\
\text { This scenario shows transmission congestion due to delays in } \\
\text { the construction of transmission lines. Also, it presents a continuing } \\
\text { increase of 2.3 GW in wind contracting. } \\
\text { This scenario assumes a steady increase of } 2.3 \mathrm{GW} \text { in wind power } \\
\text { contracts. While for transmission lines assumes a suitable capacity } \\
\text { without congestion. }\end{array}$ \\
\hline
\end{tabular}

\section{RESULTS AND DISCUSSIONS}

Understanding the dynamic of the wind-power supply chain is a vital factor in the design of strategies and added value creation. Additionality, for policy-makers, is essential to acknowledge those barriers to expansion and the consequent needs for subsidies among the actors in the supply chain [37]. This section provides a model-based analysis that simulates auction policy related to operational capacity, average inventory level and capacity of response of supply chain.

\subsection{Operational capacity for wind power generation}

Efficient long-term capacity management is fundamental to the wind power supply chain as well as stakeholders. It has implications on the installed capacity of wind power, and of course, the delivery time of industry. The operational capacity is a structural decision category, dealing with dynamic capacity expansion and reduction relative to the long-term changes in electricity demand levels [38]. Table 2 shows simulation scenarios related to the operational capacity for wind power generation; considering each actor of the wind power supply chain. Simulation scenarios used for determining the suitable capacity levels (minimums and maximums) to support the generation of wind power.

Scenarios 2 and 4 show a low variation of operational capacity for the maximum levels among each actor in the wind-power supply chain, which allow them to avoid high shortages of operational capacity in the long term. While for scenarios 1 and 3 exist significantly different among operational capacity that affects the performance of each of the actors. For instance, an unbalanced increase the operational capacity between suppliers and industry cause high variation of inventories, which of course affects the delivery lead times and reliability. When the operation levelled, constant output rates are maintained during the planning horizon [38].

Table 2. Operational capacity of the wind-power supply chain

\begin{tabular}{lcccccccc}
\hline \multicolumn{1}{c}{ Actors } & \multicolumn{2}{c}{ Scenario 1 } & \multicolumn{2}{c}{ Scenario 2 } & \multicolumn{2}{c}{ Scenario 3 } & \multicolumn{2}{c}{ Scenario 4 } \\
& Min & Max & Min & Max & Min & Max & Min & Max \\
\hline Raw material suppliers & 21,11 & 27,06 & 22,06 & 25,52 & 24,11 & 29,45 & 22,06 & 31,7 \\
Components and part wind industry & 0,64 & 7,37 & 0,97 & 7,05 & 1,22 & 7,37 & 4,11 & 7,05 \\
Wind industry & 1,58 & 10,19 & 2,3 & 9,85 & 2,91 & 10,19 & 6,29 & 9,85 \\
Wind farm developers & 4,43 & 12,21 & 4,15 & 9,35 & 7,17 & 12,21 & 7,13 & 9,35 \\
\hline
\end{tabular}

The asynchrony of the supply chain could have occurred where an actor has a more operational capacity that the other [36, 39]. For instance, wind industry obtains raw materials from suppliers that have a limited capacity, which generates a shortage in some cases. Thus, the production policy involves making decisions based on the coordination of capacities to the actors of the supply chain. This condition occurs when political decisions coordinated. Consequently, coordination of political decision plays an essential role in the dynamics of the actors of the supply chain. 


\subsection{Average inventory level of the wind-power supply chain}

One of the most common dynamic decision-making task is the regulation of inventory for the supply chain [40, 41]. In this sense, the decision-maker's objective is maintaining inventories for production along the supply chain at a sufficient level, or at least within an acceptable range. Figure 3 shows the average inventory levels under different scenarios. An unsynchronised policy generates large fluctuations causing a delay in operations on the energy system. Scenarios 1, 2 and 3, present large fluctuations of the average inventory levels in first years, while scenario 4 shows a levelled behaviour in this same periods.

The cancellation of auctions in wind power and delays in construction of transmission lines are a drawback that affects sufficient inventory levels to build of wind farms; this is more visible in scenarios 1 , 2 and 3. The lower inventory levels happening in 6 years after the simulation start time causes the response time to decrease abruptly to under construction of installed capacity for wind power. This situation generates that many component suppliers face a bleak outlook starting in 2024, which will likely last more time. Higher average inventory levels principally affect on suppliers, thus for scenarios 2 and 4 the increase of wind auctions and reduction of transmission congestion leads to lower uncertainty of supply in comparison with scenarios 1 and 3. Therefore, enforcing penalties for non-compliance could reduce the transmission congestion associated with projects delays.

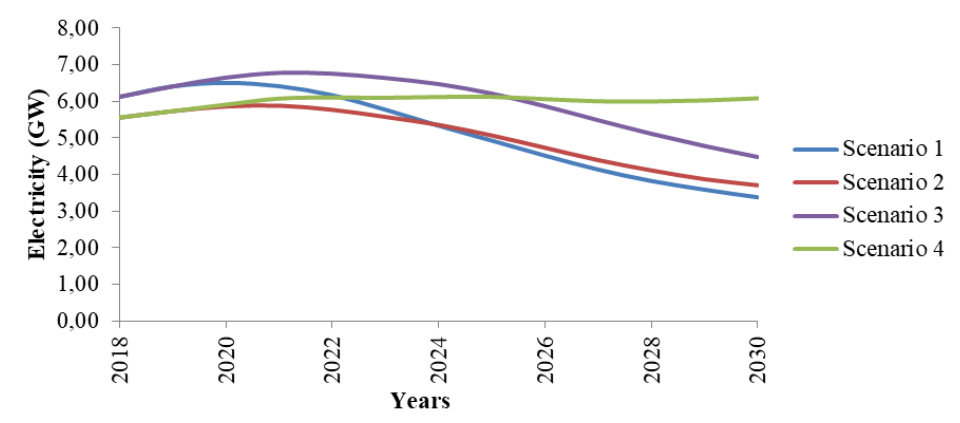

Figure 3. Dynamics of the average inventory level of the wind-power supply chain

\subsection{Capacity level of response of the wind-power supply chain}

Capacity level of response is a measure of response degree of capacity used to obtain the desired production. This measure is the relation between capacity utilisation and desired production. The aim is to achieve a uniform and high utilisation of production resources, including a minimisation of backlog related to changes in policy. Thus, different scenarios were evaluated according to changes in auctions policy and conditions of transmission infrastructure. Figure 4 show how, under scenarios 1, 2 and 3, large fluctuations, with significantly increase of response degree does not allow balanced capacity utilisation. As it can be observed in scenario 1, the capacity shortage is likely to happen between 2021 and 2025 as the result of current cancellation of wind auctions and delays in construction of transmission lines. In the BAU scenario, the response degree of capacity fluctuates at higher levels, between 0.93 and 2.04, while scenario 3 the range is from 0.90 and 1.71 and scenario 2 is from 0.85 and 1.59 . Note that policy evaluated by scenario 4 confers more excellent stability and reliability on the supply chain. This is because due to hight-frenquency response regarding the demand orders, there is a decrease in backorder along the supply chain.

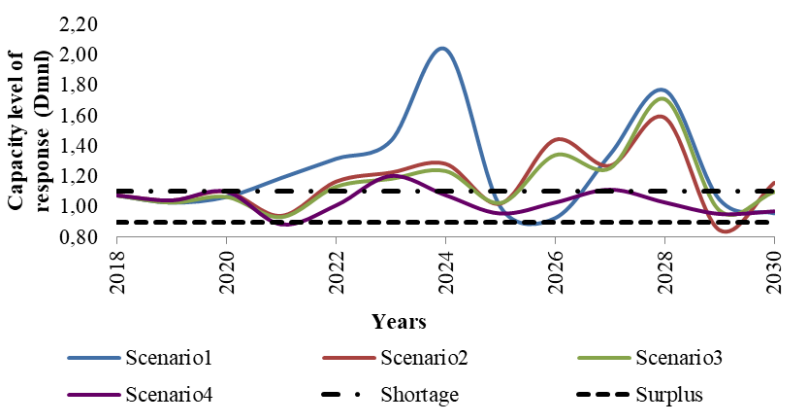

Figure 4. Capacity level of response of the wind-power supply chain 
Decisions regarding strategy in wind industry shall be altered by the response degree of the supply chain. These decisions based on the trade-off between surpluses degree associated with idle capacity and shortages degree associated with scarcity capacity. These explain how scenario 4 proposes better system performance from the perspective of capacity utilisation in the long term. In this sense, coordinated auctions policy positive influence on the performance of wind-power supply chain. These effects are noticeable in scenario 4 , where higher capacity utilisation is tied to lower variability of response degree.

\section{CONCLUSION}

This paper discusses the effects of infrastructure delays on the wind-power supply chain development. The aim of this research evaluates alternatives for mitigating asynchrony of the wind-power supply chain. The results of our analysis suggest that the expansion of the wind-power supply chain depends on coordination among actors as well as joint planning of transmission infrastructure and capacity generation. In the long term, the transmission infrastructure must be restructured to meet changing requirements and eventually yield an efficient integration of renewable energy generation [42, 43]. Although Brazil account with the highest potential of wind power [16, 44, 45], from our results found that coordination of energy policy is a crucial aspect for obtaining the reduction of asynchrony on the supply chain.

\section{ACKNOWLEDGEMENTS}

This research was partly supported by the Economic Sciences Research Centre at the Universidad Militar Nueva Granada, Federal University of Santa Catarina - SINERGIA group, and Universidad Jorge Tadeo Lozano. The authors thank two anonymous referees for their valuable comments.

\section{REFERENCES}

[1] X. Liu and M. Zeng, "Renewable energy investment risk evaluation model based on system dynamics," Renew. Sustain. Energy Rev., vol. 73(Nov. 2016), pp. 782-788, 2017.

[2] L. P. Nogueira De Oliveira et al., "Critical technologies for sustainable energy development in Brazil: Technological foresight based on scenario modelling," J. Clean. Prod., vol. 130, pp. 12-24, 2016.

[3] A. A. Juárez, A. M. Araújo, J. S. Rohatgi, and O. D. Q. De Oliveira Filho., "Development of the wind power in Brazil: Political, social and technical issues," Renew. Sustain. Energy Rev., vol. 39, pp. 828-834, 2014.

[4] M. P. De Arce, E. Sauma, and J. Contreras., "Effects of Transmission Congestion on Different Incentive Policies for Renewable Energy," J. Energy Eng., vol. 143(1), 2016.

[5] C. Hitaj., "Location matters: The impact of renewable power on transmission congestion and emissions," Energy Policy, vol. 86, pp. 1-16, 2015.

[6] C. Ochoa, I. Dyner, and C. J. Franco., "Simulating power integration in Latin America to assess challenges, opportunities, and threats," Energy Policy, vol. 61, pp. 267-273, 2013.

[7] M. M. Herrera, I. Dyner, and F. Cosenz., "Effects of the penetration of wind power in the Brazilian electricity market," Rev. Ing. Ind., vol. 15(3), pp. 309-319, 2017.

[8] G. Prostean, A. Badea, C. Vasar, and P. Octavian., "Risk Variables in Wind Power Supply Chain," Procedia - Soc. Behav. Sci., vol. 124, pp. 124-132, 2014.

[9] M. M. Herrera, I. Dyner, and F. Cosenz., "Alternative Energy Policy for Mitigating the Asynchrony of the WindPower Industry's Supply Chain in Brazil," in Innovative Solutions for Sustainable Supply Chains, H. Qudrat-Ullah, Ed. Cham: Springer International Publishing, pp. 199-221, 2018.

[10] H.-M. Wee, W.-H. Yang, C.-W. Chou, and M. V. Padilan., "Renewable energy supply chains, performance, application barriers, and strategies for further development," Renewable Sustain. Energy Rev., vol. 16(8), pp. 5451-5465, 2012.

[11] A. Aslani, P. Helo, and M. Naaranoja., "Role of renewable energy policies in energy dependency in Finland: System dynamics approach," Appl. Energy, vol. 113, pp. 758-765, 2014.

[12] R. C. Da Silva, I. De Marchi Neto, and S. Silva Seifert., "Electricity supply security and the future role of renewable energy sources in Brazil," Renew. Sustain. Energy Rev., vol. 59, pp. 328-341, 2016.

[13] C. Ioakimidis, N. Koukouzas, A. Chatzimichali, S. Casimiro, and A. Macarulla., "Energy policy scenarios of CCS implementation in the Greek electricity sector," Energy Procedia, vol. 23(x 2704), pp. 354-359, 2012.

[14] C. R. Gómez, S. Arango-Aramburo, and E. R. Larsen., "Construction of a Chilean energy matrix portraying energy source substitution: A system dynamics approach," J. Clean. Prod., vol. 162, pp. 903-913, 2017.

[15] J. Yuan, S. Sun, J. Shen, Y. Xu, and C. Zhao., "Wind power supply chain in China," Renew. Sustain. Energy Rev., vol. 39, pp. 356-369, 2014.

[16] D. K. S. Lima et al., "Estimating the offshore wind resources of the State of Ceará in Brazil," Renew. Energy, vol. 83, pp. 203-221, 2015

[17] C. A. De Melo, G. D. M. Jannuzzi, and S. V. Bajay., "Nonconventional renewable energy governance in Brazil: Lessons to learn from the German experience," Renew. Sustain. Energy Rev., vol. 61, pp. 222-234, 2016. 
[18] P. De Jong, A. Kiperstok, A. S. Sánchez, R. Dargaville, and E. A. Torres., "Integrating large scale wind power into the electricity grid in the Northeast of Brazil," Energy, vol. 100, pp. 401-415, 2016.

[19] Agencia Nacional de Energía Eléctrica-ANEEL, 'Leiloes de Geraçao', 2017. [Online]. Available: http://www.aneel.gov.br/geracao4. [Accessed: 12-Oct-2017].

[20] P. D. Lund., "Effects of energy policies on industry expansion in renewable energy," Renew. Energy, vol. 34(1), pp. 53-64, 2009.

[21] J. I. Lewis and R. H. Wiser, "Fostering a renewable energy technology industry: An international comparison of wind industry policy support mechanisms," Energy Policy, vol. 35(3), pp. 1844-1857, 2007.

[22] A. Gorayeb, C. Brannstrom, A. J. de Andrade Meireles, and J. de Sousa Mendes, "Wind power gone bad: Critiquing wind power planning processes in northeastern Brazil," Energy Res. Soc. Sci., vol. 40(August), pp. 82-88, 2018.

[23] B. Bayer., "Experience with auctions for wind power in Brazil," Renew. Sustain. Energy Rev., vol. 81(Nov. 2016), pp. 2644-2658, 2018.

[24] R. Miranda, R. Soria, R. Schaeffer, A. Szklo, and L. Saporta., "Contributions to the analysis of "Integrating large scale wind power into the electricity grid in the Northeast of Brazil," [Energy 100 (2016) 401-415]," Energy, vol. 118, pp. 1198-1209, 2017.

[25] J. W. Forrester, Industrial dynamics. M.I.T. Press, pp. 197, 1961.

[26] S. Ahmad, R. Mat Tahar, F. Muhammad-Sukki, A. B. Munir, and R. Abdul Rahim., "Application of system dynamics approach in electricity sector modelling: A review," Renewable. Sustain. Energy Rev., vol. 56, pp. 29-37, 2016.

[27] B. K. Bala, F. M. Arshad, and K. M. Noh., System Dynamics: Modelling and Simulation. 2017.

[28] I. Dyner and E. R. Larsen, "From planning to strategy in the electricity industry," Energy Policy, vol. 29(13), pp. 1145-1154, 2001.

[29] H. Qudrat-Ullah., The Physics of Stocks and Flows of Energy Systems Applications in Energy Policy, Springer London, 2016.

[30] A. Ford., "System Dynamics and the Electric Power Industry," Syst. Dyn. Rev., vol. 13(1), pp. 57-85, 1997.

[31] J. D. Morcillo, C. J. Franco, and F. Angulo., "Delays in electricity market models," Energy Strateg. Rev., vol. 16, pp. 24-32, 2017.

[32] J. D. Sterman, Business dynamics: Systems Thinking and Modeling for a Complex World, no. December 1999. McGraw-Hill, 2000.

[33] L. F. Luna-Reyes and D. L. Andersen., "Collecting and analyzing qualitative data for system dynamics: Methods and models," Syst. Dyn. Rev., vol. 19(4), pp. 271-296, 2003.

[34] ABEEolica, Dados Mensais-Novembro de 2017, Brazil, 2017.

[35] ANEEL, "Matriz de Energía Eléctrica," Capacidad de Operación, 2017. [Online]. Available: http://www2.aneel.gov.br/aplicacoes/capacidadebrasil/OperacaoCapacidadeBrasil.cfm. [Accessed: 28-Nov-2017].

[36] M. Becerra, E. C. González, M. M. Herrera, and O. R. Romero., "Collaborative Planning Capacities in Distribution Centers," in Theory, Methodology, Tools and Applications for Modeling and Simulation of Complex Systems., L. Zhang, X. Song, and Y. Wu, Eds. Singapore: Springer Singapore, pp. 622-632, 2016.

[37] C. Wüstemeyer, R. Madlener, and D. W. Bunn, "A stakeholder analysis of divergent supply-chain trends for the European onshore and offshore wind installations," Energy Policy, vol. 80, pp. 36-44, 2015.

[38] J. Olhager, M. Rudberg, and J. Wikner., "Long-term capacity management: Linking the perspectives from manufacturing strategy and sales and operations planning," Int. J. Prod. Econ., vol. 69(2), pp. 215-225, 2001.

[39] J. Orjuela, M. M. Herrera, and W. Casilimas., "Impact analysis of transport capacity and food safety in Bogota," in Workshop Engineering Application, pp. 7-13, 2015

[40] J. D. Sterman., "Modeling Managerial Behavior: Misperceptions of Feedback in a Dynamic Decision Making Experiment," Manage. Sci., vol. 35(3), pp. 321-339, 1989.

[41] J. Orjuela-Castro, M. Herrera-Ramirez, and W. Adarme-Jaimes., "Warehousing and transportation logistics of mango in Colombia : A system dynamics model," Rev. Fac. Ing., vol. 26(44), pp. 71-85, 2017.

[42] F. Kunz and A. Zerrahn, "Benefits of coordinating congestion management in electricity transmission networks: Theory and application to Germany," Util. Policy, vol. 37, pp. 34-45, 2015.

[43] P. De Jong, A. Kiperstok, and E. A. Torres., "Economic and environmental analysis of electricity generation technologies in Brazil," Renew. Sustain. Energy Rev., vol. 52, pp. 725-739, 2015.

[44] B. Soares M.C. Borba, A. Szklo, and R. Schaeffer., "Plug-in hybrid electric vehicles as a way to maximize the integration of variable renewable energy in power systems: The case of wind generation in northeastern Brazil," Energy, vol. 37(1), pp. 469-481, 2012.

[45] P. De Jong, R. Dargaville, J. Silver, S. Utembe, A. Kiperstok, and E. A. Torres., "Forecasting high proportions of wind energy supplying the Brazilian Northeast electricity grid," Appl. Energy, vol. 195, pp. 538-555, 2017. 